\title{
The Effectiveness of Dispersed Reinforcement of Soil-Cements
}

\author{
Krystian Brasse ${ }^{1}$, Tomasz Tracz ${ }^{1}$, Tomasz Zdeb ${ }^{1}$ \\ ${ }^{1}$ Cracow University of Technology, Faculty of Civil Engineering \\ ul. Warszawska 24, 31-155 Cracow, Poland \\ krystian.brasse@pk.edu.pl
}

\begin{abstract}
The paper deals with mechanical properties of soil-cement composites made with cohesive soil and reinforced by dispersed reinforcement. The research was carried out on the basis of three soil-cement matrices whose compositions varied in terms of the volumetric fraction of cement paste and the water-cement ratio. A single type of polypropylene fibres was used as dispersed reinforcement: bundles consisting of fibrillated PP tapes. In addition, the fibres varied in terms of their length and mass fraction. The aim of the research was to demonstrate the effectiveness of the fibres tested in soil-cement matrix reinforcement. For this reason, a threepoint bending test was conducted after 28 days of curing, including the determination of the following values: residual stress $\sigma C M O D_{i}$, the limit of proportionality LOP, the modulus of rapture MOR, the total energy of fracture $\mathrm{G}_{\text {tot }}$ as well as compressive strength. The test results obtained and their analysis indicate the significant impact of the reinforcement used on the mechanical properties of fibrereinforced soil-cements.
\end{abstract}

Keywords: soil-cement, cohesive soil, dispersed reinforcement, mechanical properties

\section{Introduction}

Designing and constructing shoring for deep excavations is a difficult and very responsible geotechnical task. In current dense urban environments, new structures are required to include extensive underground spaces, and the required deep excavations must be carried out in close or immediate vicinity of existing structures whose foundations are situated at small depths below ground levels. Such excavations require suitable shoring. Their walls are exposed primarily to horizontal loads in the form of soil pressure as well as to hydrostatic pressure exerted by groundwater. Additionally, the most important element of design according to the author of [1] is the selection of soil geotechnical parameters so as to determine the required geometrical and mechanical characteristics of the wall-ground system. The solution developed must ensure the required strength, stability and safety of this system as well as limit the adverse impact of the structure on its surroundings. The geotechnical technologies most frequently used for this purpose include Larssen sheet piling, CFA (Continuous Flight Auger) or VdW (Vor Der Wand) i.e. in front of the wall piling, slurry walls, Berlin type pit lining or DSM (Deep Soil Mixing) piling. The application of each of the above methods involves multiple different restrictions and requirements. One of the methods for modifying soil properties, which partially eliminates the adverse impacts mentioned, is the introduction of cement paste and its deep mixing with soil. As a result of such treatment, a soil-cement composite is produced.

In-situ wet soil mixing is a well known and frequently used method. This method is currently implemented using several different technologies such as jet grouting, DSM columns, the combination of DSM and jet grouting techniques or the application of CSM (Cutter Soil Mixing) columns [2]. The essential purpose of deep soil mixing is to obtain a homogeneous mixture. Therefore, the CDMM (Continuous Deep Mixing Method) technology is becoming increasingly popular, and according to the authors this method creates the best conditions for obtaining a homogeneous mixture of native soil with cement paste. This method consists in cutting soil and blending it with the slurry without the need to excavate it and store it on the surface. State-of-the-art machines for performing works using the CDMM have entered the market, which produce a satisfactory level of homogeneity of the soil-cement produced as well as making it possible to obtain uniform mechanical parameters of the material over the entire depth of the barrier obtained [3].

Previous deep soil mixing technologies failed to produce a fully homogeneous material. The issue of designing soilcement compositions has not been discussed either to date, which has limited the effectiveness of the reinforcement obtained. The resulting material exhibited considerable variation in its mechanical properties. Additionally, this material tends to be brittle so its range of plastic deformation is relatively small. This characteristic is undesirable if the soil being stabilised is 
subject to lateral pressure, since the soil becomes unstable as a result of cracks emerging. Therefore, there is a need for reinforcement, primarily due to the tensile stress which is present. One currently available method of increasing the tensile strength of soil-cement involves the use of dispersed reinforcement in the form of fibres. The composite produced in this manner is referred to as fibre-soil-cement.

\section{Literature study}

The simultaneous introduction (mixing) of cement paste and dispersed reinforcement into soil is not a novelty as this method of reinforcing weak soil substrate has already been studied worldwide. Attempts have been made to assess under laboratory conditions the performance of e.g. clay stabilised with cement and reinforced with polypropylene fibres [4]. However, those tests only concerned the effect of variation in the length of polypropylene fibres and their share in the soilcement matrix on its compressive strength. Two types of fibres were tested: single fibres $(3,6,9$ and $12 \mathrm{~mm}$ long) and fibre bundles obtained from polymer textile bags $(10,20,30$ and $40 \mathrm{~mm}$ long). The percentage of fibres by mass ranged from 0 to $2.5 \%$ in steps of $0.5 \%$. The tests were carried out on cylindrical specimens $39.1 \mathrm{~mm}$ in diameter and $80 \mathrm{~mm}$ in height. The results obtained demonstrated that the presence of polypropylene fibres in the soil-cement matrix significantly improves its compressive strength and deformability. Both fibre length and mass fraction had a positive impact on the increase in strength. Fibre type is an important factor as well. In the case of the polypropylene fibre types tested, slightly better results were obtained when reinforcing the matrix with single fibres than when using fibre bundles for reinforcement.

The authors of [5] also assessed the impact of dispersed reinforcement in the form of polypropylene fibres on the compressive strength of soil-cement. Tests were conducted on cylindrical specimens as well, but those had a diameter of 70 $\mathrm{mm}$ and a height of $140 \mathrm{~mm}$. Two fibre lengths (approximately $13 \mathrm{~mm}$ and $50 \mathrm{~mm}$ ) were used and three levels of fibre volumetric proportions in the matrix were reached $(0.1 \%, 0.15 \%$ and $0.2 \%)$. According to test results, the addition of fibres increased the compressive strength of soil-cement. Higher strength during tests was observed in composites with $50 \mathrm{~mm}$ long fibres.

A more extensive research programme is presented in [6], in which mechanical properties of cohesive native soil reinforced with the use of a stabiliser and short polypropylene fibres were assessed. The scope of the tests conducted on the composite produced in this manner included not only the determination of its compressive strength, but also its tensile strength, including direct tensile strength, split tensile strength and flexural tensile strength testing. In the tests, the effect of variable dosing of fibres $\left(0,25,50,75\right.$ and $\left.100 \mathrm{~kg} / \mathrm{m}^{3}\right)$ with a constant length of $12 \mathrm{~mm}$ was determined. UCS and DTS tests were carried out on cylindrical specimens $70 \mathrm{~mm}$ in diameter and $140 \mathrm{~mm}$ in height, STS tests on cylindrical specimens 70 $\mathrm{mm}$ in diameter and $70 \mathrm{~mm}$ in height and FS tests on 250x70x70 mm cuboidal specimens. The addition of polypropylene fibres decreases the stiffness of the composite and may reduce its compressive and tensile strength under the DTS test. This was the case where $25 \mathrm{~kg} / \mathrm{m}^{3}$ of fibres were used. However, mechanical properties of soil-cements are not affected in proportion to the amount of fibres added. At 50 and $75 \mathrm{~kg} / \mathrm{m}^{3}$, mechanical properties in fact improved. In general, the presence of fibres makes soil-cement less brittle, increases its plasticity and its ability to transfer additional loads after its peak strength has been reached.

The authors of [7] touch upon the subject of improvement in the mechanical properties of soil-cement in the context of its practical application in the form of DSM columns. These are subject to bending moments, which are caused by horizontal loads from the ground; the effect of the addition of steel fibres (with lengths of 35 and $60 \mathrm{~mm}$ ) and of polypropylene fibres (with a length of $58 \mathrm{~mm}$ ) on their flexural strength and residual stresses was assessed. The quantities of both types of fibres varied, amounting to $0.5 \%, 0.75 \%$ and $1.0 \%$ by volume. During the three-point bending test carried out on 100x $100 \times 350$ $\mathrm{mm}$ rectangular beams, peak strength and residual strength were determined at L/600 and L/150 deflections. Test results demonstrate that the addition of fibres resulted in improved flexural strength as well as increased residual stress. Polypropylene fibres made it possible to achieve better results compared to steel fibres. At the same time, it was found that an increase in the amount of fibres added translated into an increase in the resulting strength. 


\section{Study objective}

The purpose of the study conducted was to determine the effectiveness of reinforcing soil-cement matrices with dispersed reinforcement in the form of polypropylene fibres. The solution is meant to enhance the performance of geoengineering structures constructed from soil-cement reinforced by means of dispersed reinforcement. Therefore, desirable outcomes included an increase in flexural tensile strength of the composites in question, while ensuring a pseudo-plastic fracture mode, which allows the composites tested to be operated further in a post-critical state. Therefore, the scope of research has been developed so that the results obtained could help optimise the composition of soil-cement composites in terms of achieving the properties required. The results obtained when modifying the composition of soils stabilised with cement paste will contribute to increasing our knowledge of mechanical properties of the composites discussed, and hence may point to possible applications of the structures produced using the "trench mixing" technology.

\section{Materials}

The research programme involved the production of a series of fibre-soil-cements differing in terms of their matrix compositions as well as the type and amount of fibres added. Three types of matrices including different amounts of cement paste $V_{z}$ and exhibiting different w/c ratio values were selected for the study. The composites in question were made of cohesive soil, which was examined and identified as loam. Table No. 1 presents the basic properties of this soil.

Table 1: Properties of the loam selected.

\begin{tabular}{|l|c|}
\hline \multicolumn{1}{|c|}{ Properties } & Value \\
\hline Particle size distribution [\% by mass] & \\
- gravel fractions $2 / 40 \mathrm{~mm}$ & - \\
- sand fractions $0.05 / 2 \mathrm{~mm}$ & 30 \\
- silt fractions $0.002 / 0.05 \mathrm{~mm}$ & 42 \\
- loam fractions $<0.002 \mathrm{~mm}$ & 28 \\
\hline Bulk density $\boldsymbol{\rho}\left[\mathrm{g} / \mathrm{cm}^{3}\right]$ & 2.08 \\
\hline
\end{tabular}

The soil-cement matrices tested were created as a result of mixing the native soil described above with cement CEM II/BS 32.5 R, which meets requirements of the standard EN 197-1:2012 and tap water. The compositions of the three soil-cement mixtures selected for testing were designed so that they exhibited adequate liquidity after mixing. Mixtures were required to be self-compacting with no segregation of ingredients. These requirements determined the amount of cement paste used and the adopted w/c ratios of the mixes produced. The liquidity of all mixtures, which was determined in accordance with [8], enabled the resulting material to be incorporated into the structure using industrial-scale methods. Characteristics of the compositions used and mechanical properties of the soil-cement matrices selected for testing are presented in Table 2.

Table 2: Basic properties of three soil-cement matrices selected for research.

\begin{tabular}{|c|c|c|c|c|c|}
\hline $\begin{array}{c}\text { Matrix } \\
\text { designation }\end{array}$ & $\begin{array}{c}\text { Paste content } \mathbf{V}_{\mathbf{z}} \\
{\left[\mathbf{d m}^{\mathbf{3}} / \mathbf{m}^{\mathbf{3}} \mathbf{]}\right.}\end{array}$ & $\begin{array}{c}\text { W/c } \\
\text { ratio }\end{array}$ & $\begin{array}{c}\text { Cement content } \\
{\left[\mathbf{k g} / \mathbf{m}^{\mathbf{3}}\right]}\end{array}$ & $\begin{array}{c}\text { Flexural strength after } \\
\mathbf{2 8} \text { days [MPa] }\end{array}$ & $\begin{array}{c}\text { Compressive strength after } \\
\mathbf{2 8} \text { days [MPa] }\end{array}$ \\
\hline $800 / 1.6$ & 800 & 1.6 & 416 & 1.1 & 4.3 \\
\hline $750 / 2.0$ & 750 & 2.0 & 323 & 0.9 & 3.5 \\
\hline $700 / 2.6$ & 700 & 2.6 & 240 & 0.7 & 2.5 \\
\hline
\end{tabular}

Polypropylene fibres in the form of bundles of fibrillated PP tape with a gross diameter of approx. 3 mm were used in combination with the matrices described above. 60 and $100 \mathrm{~mm}$ long fibres were used in the tests. The lengths of the fibres used were selected on the basis of tests of combinations of dispersed reinforcement with a soil-cement matrix, which are presented in [9]. The results of pull-out tests of PP fibres anchored in the soil-cement matrix demonstrated that already at 
anchoring lengths above $50 \mathrm{~mm}$, these fibres do not exhibit any increase in the maximum force required to pull them out of the matrix, which is the result of the structure of the fibre tested.

Polypropylene (PP) fibres are among the fibres which are most commonly used in engineering practice. They make it possible to enhance the strength of soil, reducing both its shrinkage and swelling [10]. PP fibre reinforcement may also result in greater residual strength. Their advantages include hydrophobicity, resistance to the corrosive effects of alkalis and chlorides as well as biodegradability. Attention should also be paid to their relatively low cost. Table 3 presents selected properties of polypropylene fibres used for soil reinforcement [11].

Table 3: Basic properties of the fibres selected for research purposes.

\begin{tabular}{|c|c|c|c|c|c|}
\hline $\begin{array}{c}\text { Diameter } \\
{[\boldsymbol{\mu m}]}\end{array}$ & $\begin{array}{c}\text { Specific gravity } \\
{\left[\mathbf{g} / \mathbf{c m}^{\mathbf{3}}\right]}\end{array}$ & $\begin{array}{c}\text { Modulus of } \\
\text { elasticity [GPa] }\end{array}$ & $\begin{array}{c}\text { Tensile strength } \\
{[\mathbf{M P a}]}\end{array}$ & $\begin{array}{c}\text { Length range } \\
{[\mathbf{m m}]}\end{array}$ & $\begin{array}{c}\text { Range of fibre amount used } \\
{[\% \text { by mass }]}\end{array}$ \\
\hline $23-150$ & 0.92 & $3-3.5$ & $120-450$ & $6-50$ & $0-3$ \\
\hline
\end{tabular}

\section{Methods and test results}

Two levels of fibre dosage were applied with respect to fibre-soil-cement composites: $6 \mathrm{~kg} / \mathrm{m}^{3}$ and $10 \mathrm{~kg} / \mathrm{m}^{3}$. The introduction of fibres and their mixing with the matrix resulted in a slight reduction in the liquidity of the mixes obtained; however, the resulting consistency still allowed the material to be incorporated in the intended location. Immediately after mixing, 150x150x600 mm cuboid specimens were formed. The dimensions of the specimens formed were selected so as to be representative with respect to the geometry of the fibres used. After demoulding, the specimens were tightly wrapped in foil to prevent any moisture exchange with the environment and stored under laboratory conditions at $20 \pm 2^{\circ} \mathrm{C}$.

Mechanical properties of the composites in question were tested after 28 days of curing under conditions which prevented moisture exchange between the specimen and the environment (ensuring constant specimen mass). The methodology for testing the effectiveness of dispersed reinforcement was based on the guidelines presented in standard [12]. In order to fully reflect the mode of operation of such soil-cements when combined with fibres, tensile strength under three-point bending was determined together with the determination of additional parameter values: residual stress values $\left(\sigma_{\mathrm{CMOD}}\right)$, limit of proportionality (LOP), i.e. the stress at which the matrix is destroyed, the maximum stress transferred by the dispersed reinforcement - MOR (modulus of rapture) as well as the total fracture energy $\left(\mathrm{G}_{\mathrm{tot}}\right)$. During the constant increase in beam deflection during the test, the value of the force acting on the beam $\mathrm{P}$ with an accuracy of $1.0 \mathrm{~N}$, the crack mouth opening displacement with an accuracy of $0.1 \mu \mathrm{m}$ (CMOD) (Fig. 1) and beam deflection with an accuracy of $1.0 \mu \mathrm{m}$ (Fig. 2) were recorded simultaneously. In the case of fibre concrete testing, standard [12] suggests that measurements be discontinued after CMOD has reached $4 \mathrm{~mm}$. However, due to the further increase in residual stress values recorded in the case of fibre-soilcement, tests were continued until CMOD reached $10 \mathrm{~mm}$. For this reason, residual stress values were modified in relation to the original recommendations and they were recorded at CMOD $=0.5,2.5,5.0,7.5$ and $10.0 \mathrm{~mm}$. The $\sigma_{\mathrm{LOP}}$ value was determined as the maximum stress at which the linear relationship between stress and crack mouth opening displacement was no longer observed. The $\sigma_{\mathrm{MOR}}$ ratio determines the maximum value of stress transferred by the fibres after the matrix has cracked, i.e. after the LOP point has been reached. The total fracture energy $\mathrm{G}_{\text {tot }}$ is determined as the area under the stress-strain curve until the deflection has reached $10 \mathrm{~mm}$; it is stated per unit of the cross-section area of the specimen. In order to force crack propagation, $25 \mathrm{~mm}$ deep $(\mathrm{a} 0=15 \%$ of specimen height $\mathrm{h})$ and $1 \mathrm{~mm}$ wide notches were made in the middle of the beams' length. The support span was $450 \mathrm{~mm}(\mathrm{~L}=3 \mathrm{~h})$. During the measurements, the test speed was increased from $0.2 \mathrm{~mm} / \mathrm{min}$ to $3.0 \mathrm{~mm} / \mathrm{min}$ after a deflection of $0.3 \mathrm{~mm}$ had been reached, at which deflection value matrix cracking (LOP) had been observed earlier for all composites analysed. In order to ensure the correct recording of residual stresses, counterweights (Fig. 1. and Fig. 2.) were used to compensate for the additional bending force which resulted from the weight of the beam itself. The compressive strength test was carried out on 150x150x150 mm cubes in accordance with standard [13]. 

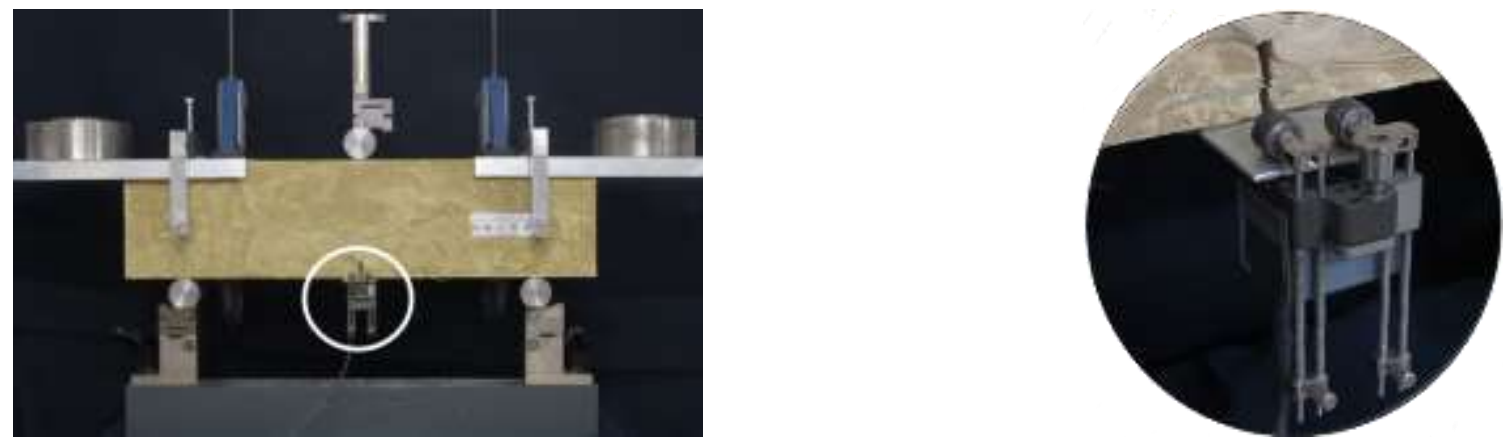

Fig. 1: Specimen during the test - CMOD (crack mouth opening displacement) measured using a clip-on extensometer.
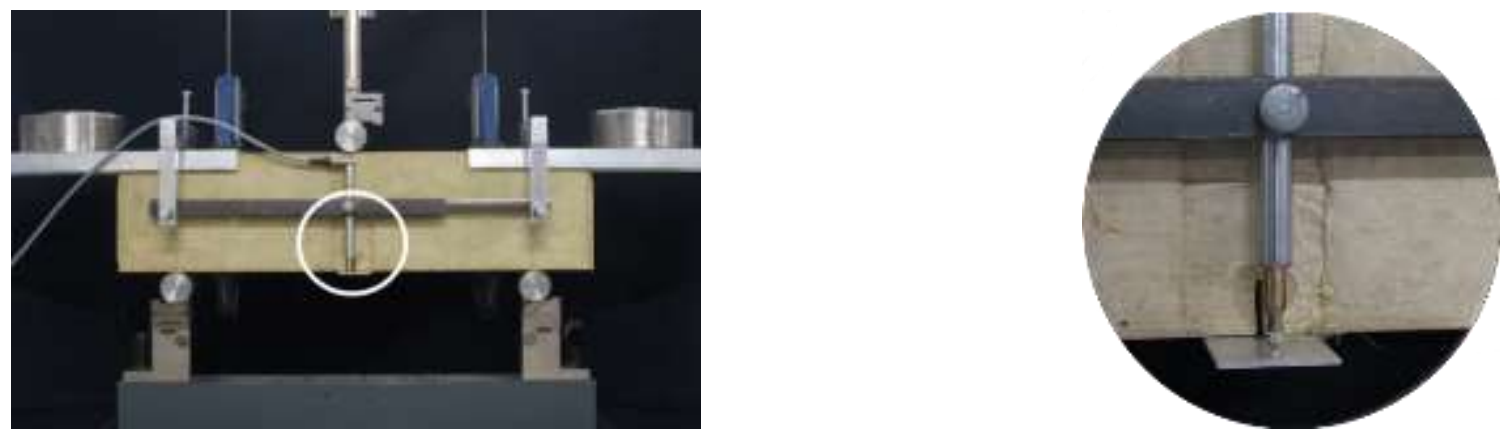

Fig. 2: Specimen during the test - deflection d measured using an inductive displacement transducer.

All the mechanical parameters determined are summarised in Table 4. Owing to the number of tests performed, partial results are not presented, and the results presented are limited to mean values from three measurements. In the case of the tests conducted here, tensile strength values under 3-point bending $\left(\mathrm{f}_{\mathrm{fm}}\right)$ are equal to MOR stress values, and therefore they have been omitted from the table which presents test results. Regardless of fibre mass fraction maximum deviation for both LOP and MOR stress values related to the average does not exceed a dozen or so percent. Table 5 shows residual stress values, which were recorded at crack mouth opening displacement CMOD $=0.5,2.5,5.0,7.5$ and $10.0 \mathrm{~mm}$, and the effectiveness of dispersed reinforcement in fibre-soil-cement composites is illustrated by the graphs shown in Fig. 3 and Fig. 4.

Table 4: Mechanical properties of fibre-soil-cement composites.

\begin{tabular}{|c|c|c|c|c|c|c|c|c|c|c|c|}
\hline \multirow[b]{2}{*}{ Matrix } & \multirow[b]{2}{*}{$\begin{array}{l}\text { Type of } \\
\text { fibre }\end{array}$} & \multicolumn{5}{|c|}{ Fibre mass fraction $6 \mathrm{~kg} / \mathrm{m}^{3}$} & \multicolumn{5}{|c|}{ Fibre mass fraction $10 \mathrm{~kg} / \mathrm{m}^{3}$} \\
\hline & & $\begin{array}{c}\mathrm{f}_{\mathrm{cm}} \\
{[\mathrm{MPa}]}\end{array}$ & $\begin{array}{c}\text { LOP } \\
{[\mathrm{MPa}]}\end{array}$ & $\begin{array}{l}\text { MOR } \\
{[\mathrm{MPa}]}\end{array}$ & $\begin{array}{c}\text { MOR/ } \\
\text { LOP }\end{array}$ & $\begin{array}{c}\mathrm{G}_{\mathrm{tot}} \\
{\left[\mathrm{kJ} / \mathrm{m}^{2}\right]}\end{array}$ & $\begin{array}{c}\mathrm{f}_{\mathrm{cm}} \\
{[\mathrm{MPa}]}\end{array}$ & $\begin{array}{c}\text { LOP } \\
{[\mathrm{MPa}]}\end{array}$ & $\begin{array}{l}\text { MOR } \\
{[\mathrm{MPa}]}\end{array}$ & $\begin{array}{c}\text { MOR/ } \\
\text { LOP }\end{array}$ & $\begin{array}{c}\mathrm{G}_{\mathrm{tot}} \\
{\left[\mathrm{kJ} / \mathrm{m}^{2}\right]}\end{array}$ \\
\hline \multirow{2}{*}{$700 / 2.6$} & $\mathrm{PP} / 60$ & 2.2 & 0.4 & 1.0 & 2.5 & 1.53 & 2.2 & 0.4 & 0.8 & 2.1 & 1.54 \\
\hline & $\mathrm{PP} / 100$ & 2.4 & 0.4 & 0.8 & 1.9 & 1.15 & 2.3 & 0.4 & 0.9 & 2.2 & 1.33 \\
\hline \multirow{2}{*}{$750 / 2.0$} & $\mathrm{PP} / 60$ & 3.0 & 0.5 & 1.1 & 2.1 & 1.71 & 3.5 & 0.5 & 1.7 & 3.3 & 2.69 \\
\hline & $\mathrm{PP} / 100$ & 3.3 & 0.5 & 0.8 & 1.6 & 1.25 & 3.4 & 0.6 & 1.4 & 2.5 & 2.11 \\
\hline \multirow{2}{*}{$800 / 1.6$} & $\mathrm{PP} / 60$ & 4.3 & 0.6 & 1.5 & 2.6 & 2.49 & 4.3 & 0.6 & 2.1 & 3.3 & 3.48 \\
\hline & $\mathrm{PP} / 100$ & 4.9 & 0.7 & 2.3 & 3.2 & 384 & 4.5 & 0.7 & 2.1 & 3.0 & 3.47 \\
\hline
\end{tabular}


Table 5: Residual stress values recorded at $\mathrm{CMOD}=0.5,2.5,5.0,7.5$ and $10.0 \mathrm{~mm}$.

\begin{tabular}{|c|c|c|c|c|c|c|c|c|c|c|c|}
\hline \multirow[b]{2}{*}{ Matrix } & \multirow[b]{2}{*}{$\begin{array}{l}\text { Type of } \\
\text { fibre }\end{array}$} & \multicolumn{5}{|c|}{ Stress values for fibre mass fraction $6 \mathrm{~kg} / \mathrm{m}^{3}[\mathrm{MPa}]$} & \multicolumn{5}{|c|}{ Stress values for fibre mass fraction $10 \mathrm{~kg} / \mathrm{m}^{3}[\mathrm{MPa}]$} \\
\hline & & $\begin{array}{c}\text { CMOD } \\
0.5\end{array}$ & $\begin{array}{c}\text { CMOD } \\
2.5\end{array}$ & $\begin{array}{c}\text { CMOD } \\
5.0\end{array}$ & $\begin{array}{c}\text { CMOD } \\
7.5\end{array}$ & $\begin{array}{c}\text { CMOD } \\
10.0\end{array}$ & $\begin{array}{c}\text { CMOD } \\
0.5\end{array}$ & $\begin{array}{c}\text { CMOD } \\
2.5\end{array}$ & $\begin{array}{c}\text { CMOD } \\
5.0\end{array}$ & $\begin{array}{c}\text { CMOD } \\
7.5\end{array}$ & $\begin{array}{c}\text { CMOD } \\
10.0\end{array}$ \\
\hline \multirow{2}{*}{$700 / 2.6$} & $\mathrm{PP} / 60$ & 0.8 & 0.9 & 0.9 & 0.9 & 0.8 & 0.6 & 0.8 & 0.7 & 0.6 & 0.5 \\
\hline & $\mathrm{PP} / 100$ & 0.5 & 0.7 & 0.7 & 0.7 & 0.7 & 0.6 & 0.8 & 0.8 & 0.7 & 0.7 \\
\hline \multirow{2}{*}{$750 / 2.0$} & $\mathrm{PP} / 60$ & 0.7 & 1.0 & 1.0 & 0.9 & 0.8 & 1.2 & 1.6 & 1.6 & 1.5 & 1.4 \\
\hline & PP/100 & 0.5 & 0.8 & 0.8 & 0.8 & 0.7 & 1.0 & 1.4 & 1.3 & 1.2 & 1.2 \\
\hline \multirow{2}{*}{$800 / 1.6$} & $\mathrm{PP} / 60$ & 1.0 & 1.5 & 1.5 & 1.4 & 1.3 & 1.4 & 2.0 & 2.0 & 2.0 & 1.8 \\
\hline & PP/100 & 1.5 & 2.1 & 2.2 & 2.2 & 2.1 & 1.4 & 1.9 & 2.0 & 2.0 & 1.9 \\
\hline
\end{tabular}

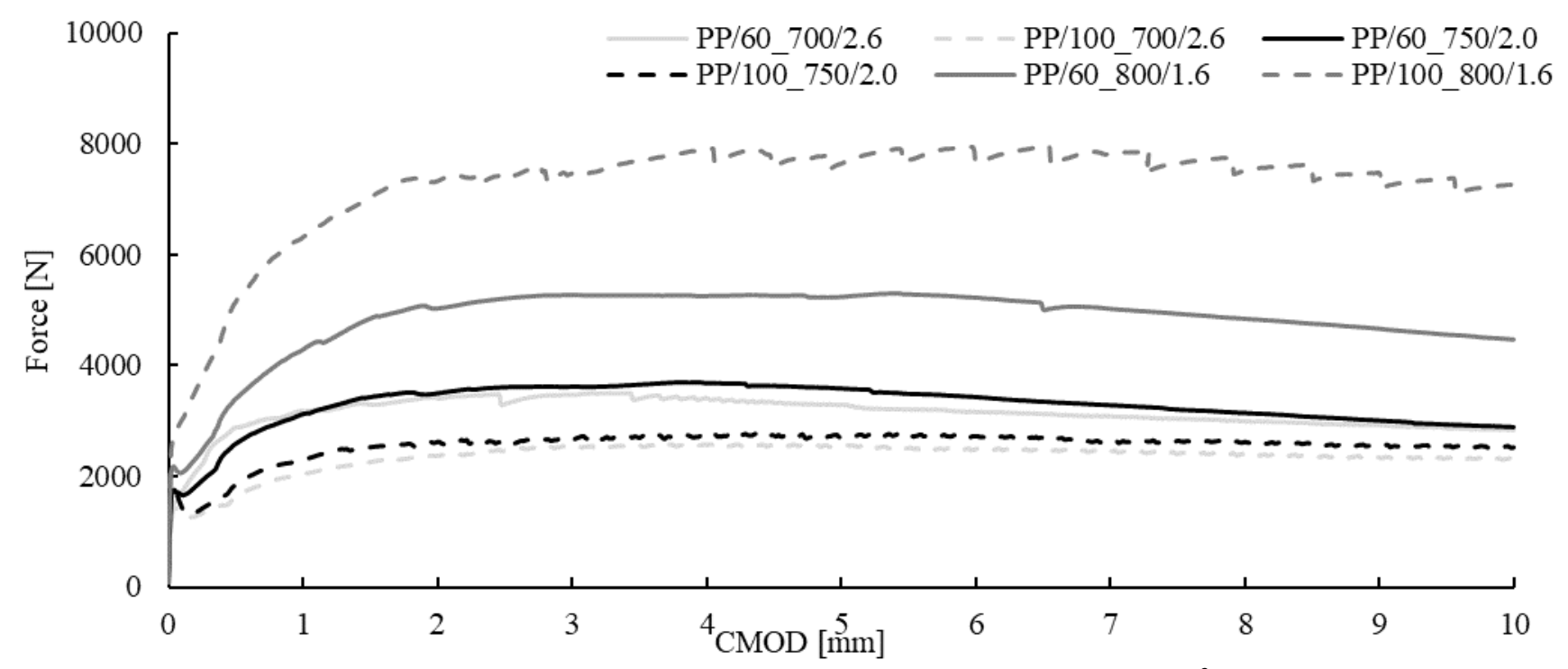

Fig. 3: Force-CMOD relationship graphs for $6 \mathrm{~kg}$ of fibres added per $\mathrm{m}^{3}$.

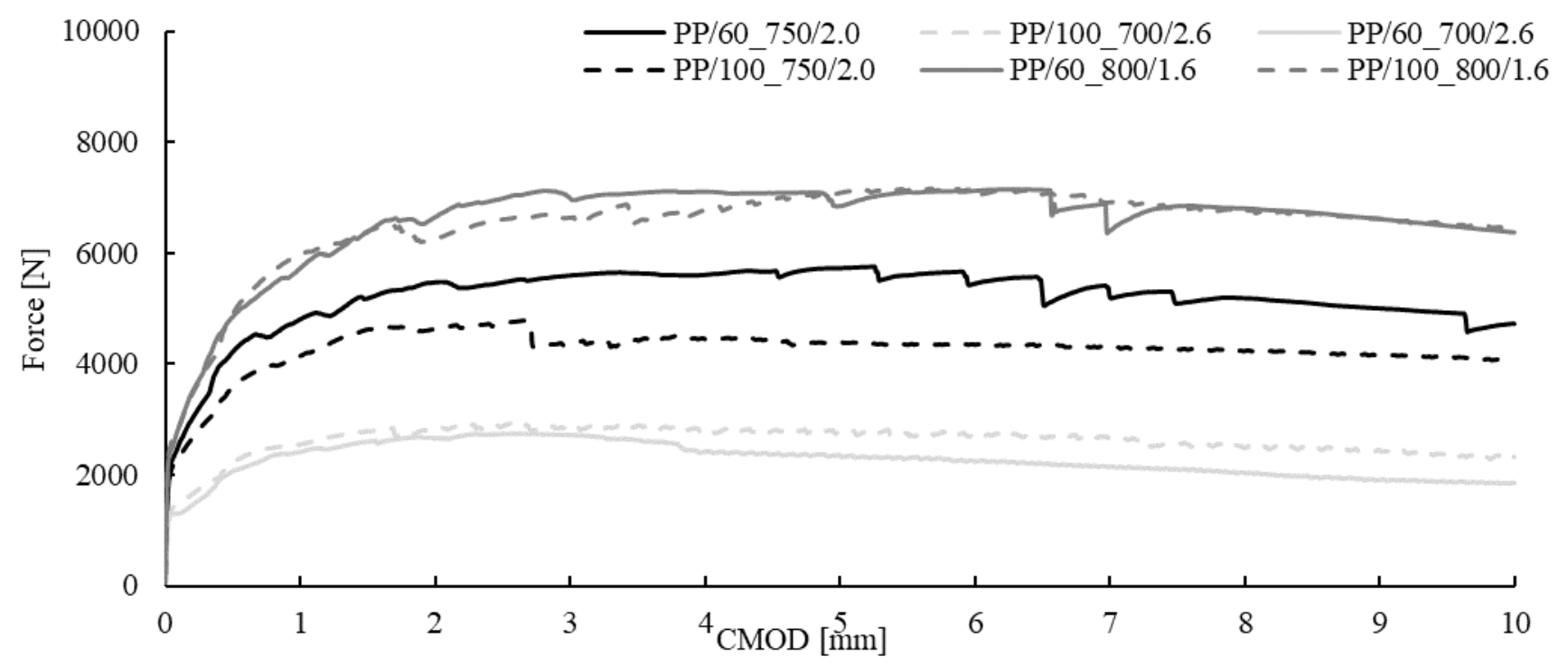

Fig. 4: Force-CMOD relationship graphs for $10 \mathrm{~kg}$ of fibres added per $\mathrm{m}^{3}$. 
The soil-cement matrices selected for testing exhibited compressive strengths in the range from 2.5 to $4.3 \mathrm{MPa}$. The differences recorded resulted from the variations in their quantitative compositions, with a natural downward trend in strength as the w/c ratio increased. After dispersed reinforcement had been introduced into the matrices, a slight decrease in compressive strength of $7 \%$ was observed. The exception were composites labelled as 800/1.6 which contained PP/60 or PP/100 fibres (at both mass fraction levels), for which the average compressive strength remained unchanged or increased slightly (by 9\%).

Unreinforced soil-cement matrices exhibited flexural tensile strength values ranging from 0.7 to $1.1 \mathrm{MPa}$. The flexural tensile strength of fibre-soil-cement composites values, which in case of these composites can be considered identical with бMOR, ranged from 0.8 to $2.3 \mathrm{MPa}$ and so increased on average by $29 \%$ in comparison to unreinforced soil-cement matrices. On the other hand, the introduction of fibres into the soil-cement matrices resulted in a decrease in LOP values by an average of $49 \%$ each time. However, the presence of the notch during fibre-soil-cement composite testing and the absence of such notch during unreinforced soil-cement testing must be emphasised here.

The values of the MOR/LOP ratio obtained during testing, which provide a measure of the degree to which soil-cement has been reinforced using dispersed reinforcement, ranged from 1.6 to 3.3. The average MOR/LOP ratio value for fibre-soilcements with $60 \mathrm{~mm}$ fibres was 2.7 and for $100 \mathrm{~mm}$ fibres it was 2.4 . The addition of $6 \mathrm{~kg} / \mathrm{m}^{3}$ of fibres resulted in an average MOR/LOP value of 2.3 , and where $10 \mathrm{~kg} / \mathrm{m}^{3}$ were added, this was 2.7. The highest average MOR/LOP ratio value of 3.0 was reached for fibre-soil-cement composites with the matrix labelled as 800/1.6. For fibre-soil-cement composites with the $750 / 2.0$ matrix, the MOR/LOP ratio was 2.4 , and for those with the 700/2.6 matrix, it was only 2.2 .

The calculated values of total fracture energy $G_{\text {tot }}$ ranged from 1.15 to $3.84 \mathrm{~kJ} / \mathrm{m}^{2}$. The average $G_{\text {tot }}$ value for fibre-soilcements with $60 \mathrm{~mm}$ fibres was $2.24 \mathrm{~kJ} / \mathrm{m}^{2}$, and for $100 \mathrm{~mm}$ fibres it was $2.19 \mathrm{~kJ} / \mathrm{m}^{2}$. Fibre-soil-cement composites with dispersed reinforcement content of $6 \mathrm{~kg} / \mathrm{m}^{3}$ exhibited an average $G_{\text {tot }}$ value equal to $2.00 \mathrm{~kJ} / \mathrm{m}^{2}$, and those with $10 \mathrm{~kg} / \mathrm{m}^{3}$ of fibres exhibited an average $G_{\text {tot }}$ of $2.44 \mathrm{~kJ} / \mathrm{m}^{2}$. The highest average $G_{\text {tot }}$ value of $3.32 \mathrm{~kJ} / \mathrm{m}^{2}$ was reached by fibre-soil-cement composites with the 800/1.6 matrix, while for the 750/2.0 matrix the average $\mathrm{G}_{\text {tot }}$ value was $1.94 \mathrm{~kJ} / \mathrm{m}^{2}$, and for the $700 / 2.6$ matrix it was $1.39 \mathrm{~kJ} / \mathrm{m}^{2}$.

The above analysis of the results makes it possible to state that $60 \mathrm{~mm}$ long fibres dosed at $10 \mathrm{~kg} / \mathrm{m}^{3}$ exhibit better performance in combination with the soil-cement matrix. This can be explained by the average distance between the fibres' centres of gravity, which is referred to as fibre spacing (s) and can be calculated according to formula (1) included in [14].

\section{where: $\quad 1-$ fibre length $[\mathrm{mm}]$}

$$
s=\sqrt[3]{\frac{\pi l d^{2}}{4 V_{f}}}
$$

$\mathrm{d}$ - net fibre diameter, $1.64 \mathrm{~mm}$ (2000tex)

$\mathrm{V}_{\mathrm{f}}-$ volume fraction of PP fibres in fibre-soil-cement [-]

According to the above equation, composites with $6 \mathrm{~kg} / \mathrm{m}^{3}$ of $60 \mathrm{~mm}$ long reinforcement had a fibre spacing of $27 \mathrm{~mm}$ and at $10 \mathrm{~kg} / \mathrm{m}^{3}$ the spacing was $23 \mathrm{~mm}$. On the other hand, for fibres with a length of $100 \mathrm{~mm}$, their spacing amounted to $32 \mathrm{~mm}$ at $6 \mathrm{~kg} / \mathrm{m}^{3}$ and to $27 \mathrm{~mm}$ at $10 \mathrm{~kg} / \mathrm{m}^{3}$, respectively. Therefore, a lower fibre spacing value translates into a greater number of fibres per unit of cross-section area, which results in a more effective operation of dispersed reinforcement.

The fibre-soil-cement composites tested exhibit a high ratio of flexural tensile strength to compressive strength. This ratio was on average 0.42 for $60 \mathrm{~mm}$ long fibres, 0.40 for $100 \mathrm{~mm}$ fibres, 0.37 for $6 \mathrm{~kg} / \mathrm{m}^{3}$ of fibres and $0.43 \mathrm{for} 10 \mathrm{~kg} / \mathrm{m}^{3}$ of fibres. Depending on the soil-cement matrix used, the $\mathrm{f}_{\mathrm{cm}} / \mathrm{f}_{\mathrm{fm}}$ ratio amounted to 0.44 for the 800/1.6 matrix, 0.38 for the 750/2.0 matrix and 0.39 for the 700/2.6 one. For comparison, in non-reinforced composites, the ratios were as follows: 0.26 for soil-cement labelled as 800/1.6, 0.26 for 750/2.0 soil-cement and 0.28 for the 700/2.6 one, which means an average increase of $53 \%$.

Analysing residual stress values, it can be stated that for the fibre lengths and amounts tested, these reach their maximum level within the CMOD (crack mouth opening displacement) range from 2.5 to $7.5 \mathrm{~mm}$, which confirms that the CMOD range adopted for testing fibre-soil-cement composites was appropriate. 


\section{Conclusion/Summary}

The current level of development of CDMM deep soil mixing makes it possible to obtain homogeneous fibre-soil-cement composites in geotechnical projects. It is therefore reasonable to design the compositions of these materials in order to enhance the performance of geoengineering structures made from fibre-soil-cement composites. The application of dispersed reinforcement in the form of polypropylene fibres increases flexural tensile strength of fibre-soil-cement composites in comparison to unreinforced soil-cement matrices. This effect is present to varying degrees for both lengths and both mass fraction levels of fibres in the resulting composites. The dispersed reinforcement used in soil-cement matrices results in the pseudo-plastic fracture mode of the composites investigated and enables them to operate further in the post-critical state. The effectiveness of dispersed reinforcement is also strongly dependent on the mechanical parameters of the reinforced soilcement. The stronger the soil-cement matrix, the more effective the inclusions. Summing up, the level of reinforcement obtained and the significant improvement in the ratio of flexural tensile strength to compressive strength of fibre-soil-cement composites opens new possibilities for their application in practice.

\section{References}

[1] A. Siemińska-Lewandowska, "Projektowanie ścian głębokich wykopów - teoria i praktyka," Geoinżynieria Drogi. Mosty Tunele, vol. 2006, no. 09, pp. 16-23, 2006.

[2] M. Topolnicki, "In situ Soil Mixing," in Ground Improvement, M. Moseley and K. Kirsch, Eds. London i New York: Spon Press, 2004, pp. 331-428.

[3] P. Głowacki, "Trenchmix ${ }^{\circledR}$ - możliwości zastosowania w budownictwie infrastrukturalnym, kubaturowym i hydrotechnicznym," XVI Seminarium WZMACNIANIE PODŁOŻA I FUNDAMENTOWANIE, 2017.

[4] M. Chen, S.-L. Shen, A. Arulrajah, H.-N. Wu, D.-W. Hou, and Y.-S. Xu, "Laboratory evaluation on the effectiveness of polypropylene fibers on the strength of fiber-reinforced and cement-stabilized Shanghai soft clay," Geotextiles and Geomembranes, vol. 43, no. 6, pp. 1-9, 2015.

[5] N. Cristelo, V. M. C. F. Cunha, M. Dias, A. T. Gomes, T. Miranda, and N. Araujo, "Influence of discrete fibre reinforcement on the uniaxial compression response and seismic wave velocity of a cement-stabilised sandy-clay," Geotextiles and Geomembranes, vol. 43, no. 1, pp. 1-13, 2015.

[6] A. A. S. Correia, P. J. Venda Oliveira, and D. G. Custódio, "Effect of polypropylene fibres on the compressive and tensile strength of a soft soil, artificially stabilised with binders," Geotextiles and Geomembranes, vol. 43, no. 2, pp. 97-106, 2015.

[7] P. Sukontasukkul and P. Jamsawang, "Use of steel and polypropylene fibers to improve flexural performance of deep soil-cement column," Construction and Building Materials., vol. 29, pp. 201-205, 2012.

[8] PN-EN 1015-3: 2000 Methods of test for mortar for masonry - Part 3: Determination of consistence of fresh mortar (by flow table).

[9] T. Zdeb, T. Tracz, K. Brasse, and E. Sałapat, "Analysis of reinforcement anchors in a soil-cement matrix - part II," Magazyn Autostrady, vol. 10, pp. 74-78, 2017.

[10] A. S. Soğanc1, "The Effect of Polypropylene Fiber in the Stabilization of Expansive Soils," International Journal of Geological and Environmental Engineering, vol. 9, no. 8, pp. 956-959, 2015.

[11] S. M. Hejazi, M. Sheikhzadeh, S. M. Abtahi, and A. Zadhoush, "A simple review of soil reinforcement by using natural and synthetic fibers," Construction Building Materials, vol. 30, pp. 100-116, 2012.

[12] PN-EN 14651:2007 Test method for metallic fibre concrete - Measuring the flexural tensile strength (limit of proportionality (LOP), residual).

[13] PN-EN 12390-3: 2011 Testing hardened concrete - Part 3: Compressive strength of test specimens.

[14] M. A. Glinicki, "Beton ze zbrojeniem strukturalnym,” XXV Ogólnopolski Warsztaty Pracy Projektanta Konstrukcji, pp. 279-308, 2010. 